\section{A Novel Intersectional Buddleja Hybrid}

Jon T. Lindstrom, ${ }^{1}$ Gregory T. Bujarski, and Brent M. Burkett Department of Horticulture, University of Arkansas, 316 Plant Sciences Building, Fayetteville, AR 72701

Additional index words. Buddleja indica, Buddleja davidii, interspecific hybridization, butterfly bush, Loganiaceae

Abstract. Buddleja indica Lam. is encountered frequently as a houseplant or a conservatory specimen and is attractive ornamentally for its oak-shaped foliage. Buddleja indica, a tetraploid African species, $2 n=76$, was crossed to the Asiatic tetraploid species $B$. davidii Franch. The $F_{1}$ generation was intermediate in foliage character between the two parents. Flowers of the $F_{1}$ were either white or light lavender in color and the number of flowers per inflorescence was intermediate between the parents. The $F_{1}$ plants were fertile. These hybrids might be suitable for greenhouse or container culture due to their attractive foliage and floral display.

The genus Buddleja L. [syn. Buddleia L. of the Loganiaceae C. Mart. (syn. Buddlejaceae Wilhelm)] consists of $\approx 100$ species found in Asia, Africa, and North and South America (Leeuwenberg, 1979; Norman, 2000). Historically, taxonomists have disagreed about the use of an $-i$ versus a $-j$ when spelling the generic name. The American Society of Horticultural Science recently adopted Griffths (1994) as the modern source for scientific names. Griffiths (1994) and two recent taxonomic treatments of the genus (Leeuwenberg, 1979; Norman, 2000) all cite the genus as Buddleja, the name used herein. Leeuwenberg (1979) separated the genus into four sections: Buddleja, Chilianthus (Burch.) Leeuw., Neemda Benth., and Nicodemia (Tenore) Leeuw. Norman (2000) recognized two sections in Buddleja: Nicodemia and Buddleja. She considered Chilianthus Burch to be a separate genus and combined sect. Neemda and Buddleja of Leeuwenberg (1979) into sect. Buddleja.

Most cultivated species of Buddleja are Asiatic in origin and in sect. Buddleja.Buddleja davidii Franch., the butterfly bush, native to China and Japan, is the most commonly grown species with many cultivars and is assigned to Buddleja sect. Buddleja. Section Nicodemia encompass species that have a berry as a fruit, rather than a capsule. Two members of this section are cultivated. Buddleja indica Lam. is known as the parlor oak and is native to the Comoro and Mascarene Islands and Madagascar (Leeuwenberg, 1979). It is cultivated as a houseplant for its attractive, glossy, dark green, oak-shaped foliage. The other member of the section found in cultivation is B. madagascarensis Lam. It is a large-growing plant with panicles of orange, noisome (in some clones) flowers that open in winter and continue through spring. The hybrid B. xlewisiana Everett (Maunder, 1987) had been described between the latter species and B. asi-

Received for publication 19 Mar. 2003. Accepted for publication 10 July 2003. We acknowledge Longwood Gardens, Kennett Square, Pa., who provided partial support for this project.

${ }^{1}$ To whom reprint requests should be addressed; e-mail tranell@uark.edu. atica Lour. (sect. Buddleja).Also, Leeuwenberg (1979) reported on a natural hybrid between $B$. madagascarensis and $B$. indica.

Interspecific hybridization in Buddleja was reported first by Van De Weyer in the 1910s when he crossed B. globosa Hope. with $B$. davidii to creDe Weyer, 1920). Cultivars of this hybrid ('Golden Glow', 'Moonlight', 'Sun Gold', and 'Honeycomb') are grown today (Dirr, 1998). Moore (1949) reported on a series of interspecific Buddleja hybrids he produced in the 1940s. Species used in his breeding work included $B$. alternifolia Maxim., B. asiatica $B$. stenostachya Reh. et Wils., $B$. salviifolia Lam., and B. lindleyana Fort. (Moore, 1949). Leeuwenberg (1979) and Maunde (1987) published extensive list of known interspecific Buddleja hybrids; however, recent hybridization in Buddleja has been restricted to either $B$. davidii or B. fallowiana Balf. f. (Tobutt, 1993). Many Buddleja species possess ornamental cultura attributes lacking in selections of $B$. davidii. These characters include orange or yellow flowe color, pronounced foliage and stem pubescence, interesting foliage shape, heat tolerance, and disease resistance. Our objective is to report on an artificial interspecific Buddleja hybrid between two different sections, Buddleja and Nicodemia. Such crosses may be useful to introduce the unique foliage and fruiting characteristics of $B$. indica into $B$. davidii cultivars.

Both $B$. davidii and B. indica are tetraploids $(2 n=76)$ (Gadella, 1962; Moore, 1947, 1960). Buddleja indica is the only known ate $B$. xweyeriana Weyer (Van
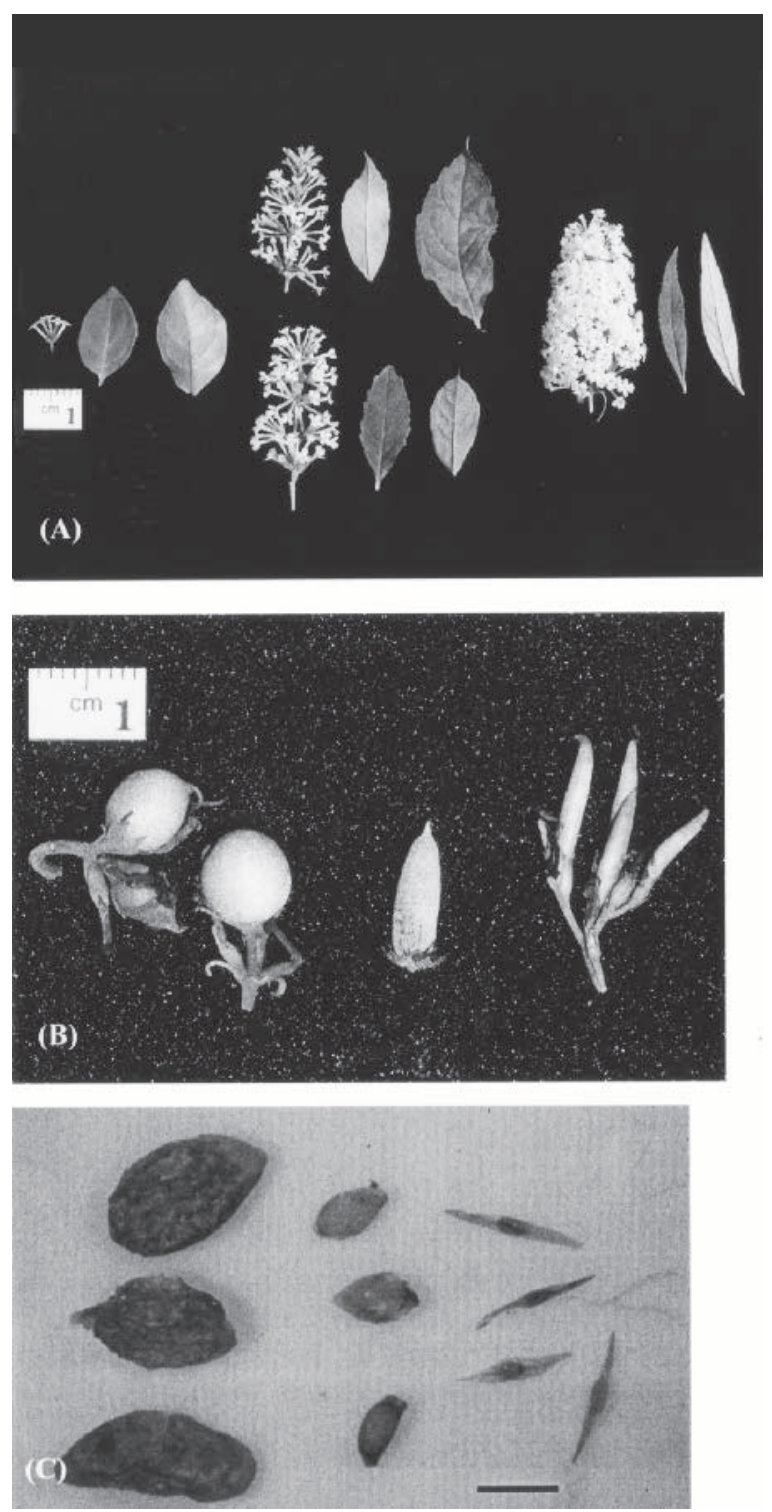
Table 1. Morphological measurements (mean $\pm 1 \mathrm{sD}, \mathrm{n}=10$ ) of progeny and parents of the interspecific Buddleja davidii 'White Bouquet' $\mathrm{x}$ B. indica cross.

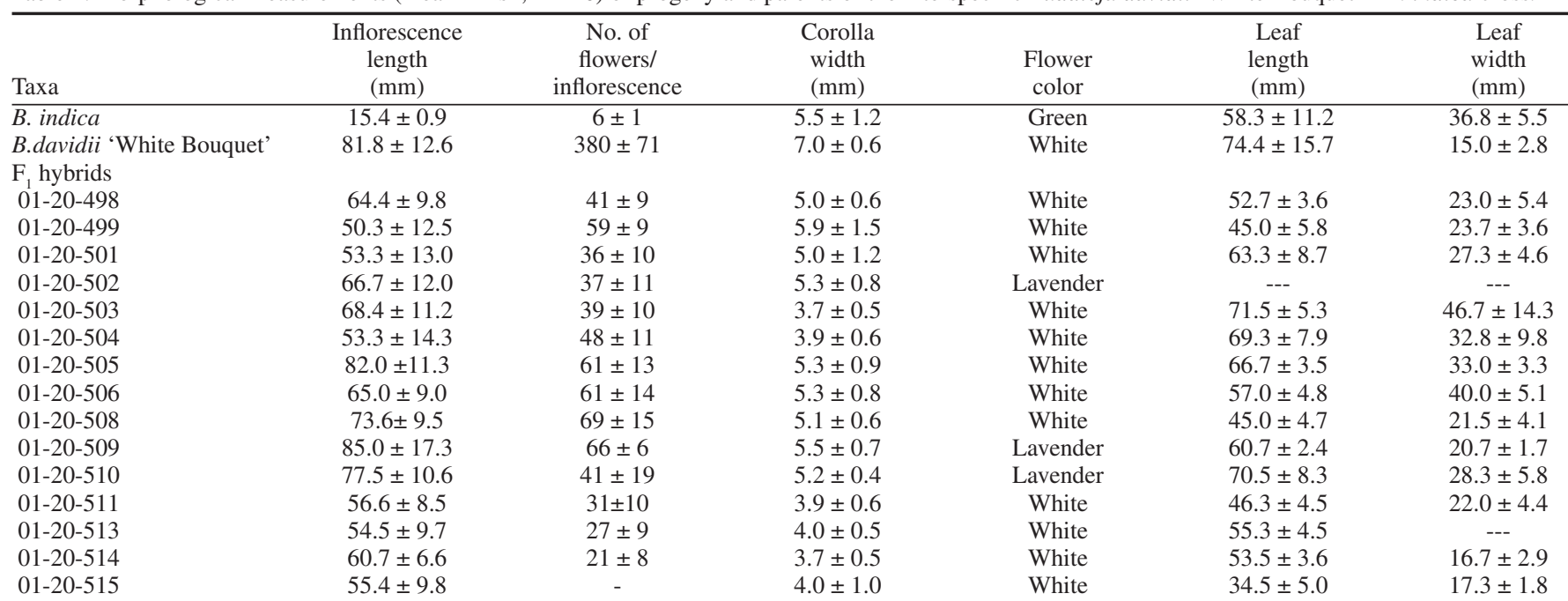

davidii. Two days after emasculation, pollen from $B$. indica was applied to the stigmatic surface of $B$. davidii 'White Bouquet'. Seeds from capsules of $B$. davidii 'White Bouquet' were harvested and sown in mid winter (Feb. 2001, $\approx 4$ months after the cross was made).

Characterization of $F_{1}$ hybrids. Morphological measurements (inflorescence length, number of flowers per inflorescence, corolla width, flower color, leaf length, and leaf width) of the $\mathrm{F}_{1}$ progeny and parents were taken during the following fall and winter from plants growing in the greenhouse. The flower color and measurements for each of the characters listed were taken and the mean and standard deviation were calculated.

\section{Results and Discussion}

Eighteen putative $F_{1}$ seedlings were obtained from the cross of $B$. davidii 'White Bouquet' $x B$. indica. Although the reciprocal cross was made, no fruit were produced on $B$. indica. Progeny began to flower 7 months after sowing (September 2001) and the last $F_{1}$ plant flowered for the first time 16 months after sowing. Plants were maintained in the greenhouse, and flowering times coincided with those of $B$. davidii and B. indica. Appearance of flowers, foliage, and fruit for both parents and two examples of $F_{1}$ progeny are shown in Fig. 1. Morphological measurements for $15 \mathrm{~F}_{1}$ plants are shown in Table 1. Three plants died before flowering due to cultural mishaps. In general, $\mathrm{F}_{1}$ plants were intermediate in appearance between the two parents. Flower color was either white or light lavender. The intensity of the lavender color varied due to ambient temperature and color was more intense in the fall with cooler night temperatures. Fragrance was noted in the flowers of $F_{1}$ plants. The scent was peppery, unlike the honey-like floral fragrance of $B$. davidii 'White Bouquet'. Flowers on our clones of $B$. indica are unscented.

Number of flowers per inflorescence of the
$F_{1}$ was intermediate between the two parents (Table 1). The clone of B. indica used in this cross averaged six flowers per cyme. Floral display in the $\mathrm{F}_{1}$ hybrid was sparse as compared to $B$. davidii cultivars. This problem needs to be addressed in future breeding. Other clones of $B$. indica have a terminal inflorescence like that found in B. davidii; however, these genotypes may not be in cultivation (Leeuwenberg, 1979). $\mathrm{F}_{1}$ progeny of the B. davidii 'White Bouquet' $x B$. indica cross were fertile. These progeny have been backcrossed successfully to both parents and have been sib-crossed (data not presented). Then, progeny could be selected for both high flower numbers and attractive oak-shaped leaves.

The fruit that developed on the $\mathrm{F}$, hybrid are unique for a Buddleja spp. (Fig. 1B). It was intermediate between the two parents, but unlike $B$. davidii, the fruit did not dehisce upon maturity. Fruit on plants grown in the field do not develop the fleshy or juicy character observed in $B$. indica. However, in greenhouse-grown material, the fruit developed a juicy character $\approx 5$ months after pollination.

Also, seed from $\mathrm{F}_{1}$ plants are intermediate between the parents both in size and in the presence of the wing observed on $B$. davidii (Fig. 1C). It is unlikely, given the size of the wing compared to the size of the seed, that seeds of the $\mathrm{F}$, would be disseminated far by wind, as occurs in most Buddleja spp., including B. davidii (Norman, 2000). Presumably, because of its long-winged seeds, this species has become weedy in many places (Anisko and Im, 2001). Incorporating seed characteristics of $B$. indica into hybrids with $B$. davidii may reduce the invasive ability found currently with this species.

Plants of the $F$ hybrid were planted outdoors in full sun in Fayetteville, Ark. As with greenhouse plants, they flowered heavily in late summer and early fall. Due to the tropical nature of $B$. indica, it is unlikely that this hybrid will survive winters in USDA Cold Hardiness
Zone $6 \mathrm{~b}$. However, they may be suitable for warmer regions. Also, It would be worthwhile to investigate the suitability of this hybrid for container or greenhouse culture since some genotypes exhibit a restrained growth habi and attractive foliage. These hybrids were easy to propagate from cuttings taken in summer, following procedures cited for $B$. davidii. (Dirr and Heuser, 1987).

\section{Literature Cited}

Anisko, T. and U. Im. 2001. Beware of butterfly bush Amer. Nurseryman 194(2):46-49.

Dirr, M. 1998. Manual of woody landscape plants: Their identification, ornamental characteristics, culture, propagation and uses. $5^{\text {th }}$ ed. Stipes Publ., Champaign, Ill

Dirr, M.A. and C.W. Heuser, Jr. 1987. The reference manual of woody plant propagation: From seed to tissue culture. Varsity Press, Athens, Ga.

Gadella, T.W.J. 1962. Some cytological observations in the Loganicaeae. Acta Bot. Neerlandica 11:51-55.

Griffiths, M. 1994. Index of garden plants. Timber Press, Portland, Ore

Keenan, J. 1969. Notes on Buddleia II: Pollen. Notes Roy. Bot. Garden Edinburgh 29:199-202.

Leeuwenberg, A.J.M. 1979. The Loganiaceae of Africa XVIII. Buddleja L. II. Revision of the African and Asiatic species. Meded. Landbouwhoogeschool 79:1-163.

Maunder, M. 1987. Notes on tender species of Buddleia. The Plantsman 9(2):64-80.

Moore, R.J. 1947. Cytotaxonomic studies in the Loganiaceae. I. Chromosome numbers and phylogeny in the Loganiaceae. Amer. J. Bot. 34:527-538

Moore, R.J. 1949. Cytotaxonomic studies in the Loganiaceae III. Artificial hybrids in the genus Buddleja L. Amer. J. Bot. 36:511-516.

Moore, R.J. 1960. Cytotaxonomic notes on Buddleia. Amer. J. Bot. 47:511-517.

Norman, E. M. 2000. Buddlejaceae. Flora Neotropica Monogr. 81:1-225.

Tobutt, K.R. 1993. Inheritance of white flower color and congested growth habit in certain Buddleia progenies. Euphytica 67:231-235.

Van De Weyer, W. 1920. Hybrid Buddleias. Gardeners' Chron. 68(Ser. 3): 181. 